\title{
The Trend and Influencing Factors of Potential Evapotransp- iration in the Yellow River
}

\author{
Yanyu Dai ${ }^{1,2}$, Fan $\mathrm{Lu}^{1}$, Kui Zhu ${ }^{2}$, Xinyi Song ${ }^{1}$, and Yiran $\mathrm{Xu}^{1,2}$ \\ ${ }^{1}$ Water Resources Institute, China Institute of Water Resources and Hydropower Research, Beijing 100038, China \\ ${ }^{2}$ School of Resources and Geosciences, China University of Mining and Technology, Xuzhou 221116, China
}

\begin{abstract}
Based on the Penman-Monteith formula recommended by the World Food and Agriculture Organization (FAO) and the Mann-Kendall trend test method, the variation trend of potential evapotranspiration in the Yellow River Basin from 1952 to 2014 is analyzed. The results showed that the potential evapotranspiration of $43.3 \%$ of the 90 meteorological stations in the Yellow River Basin showed a significant upward trend. $30 \%$ of the stations showed a significant downward trend, and $26.7 \%$ of the stations had no obvious trend of change. In all the secondary areas of water resources, the stations above Longyangxia are basically marked upward. The Longyangxia to the northern part of Lanzhou, the Longmen to the east of Sanmenxia and the Sanmenxia to Huayuankou are all significant descending sites. The change trend of the sites below the Huayuankou is not obvious. In other partition three kinds of sites are distributed. Through the correlation analysis, it is found that the increase of temperature has a great influence on the stations where the potential evapotranspiration is significantly increased, and the decrease of wind speed is the main reason for the significant decrease of potential evapotranspiration in some stations.
\end{abstract}

\section{Introduction}

Evaporation, as an important part of water cycle, plays an important role in global water balance, water cycle and energy transfer. Potential evapotranspiration refers to the maximum evapotranspiration of a fixed underlying surface, also known as reference crop evapotranspiration, when water supply is not restricted under certain meteorological conditions, which is the key factor in estimating ecological water demand and agricultural irrigation. Under the background of global warming, the meteorological conditions in China have changed significantly in the past 50 years. Potential evapotranspiration is affected by wind speed, air temperature, radiation, relative humidity and other factors, and it is a hot research topic in the world. Many scholars have done a lot of research on the spatiotemporal variation of potential evapotranspiration and its sensitivity, but the results are different in different regions. Liu et al. ${ }^{[4]}$ found that the potential evapotranspiration of Yellow River basin increased from 1960 to 2007, and the potential evapotranspiration was most sensitive to the highest temperature. Zhao et al. ${ }^{[5]}$ calculated the potential evapotranspiration of Haihe River Basin by using four potential evapotranspiration models, and found that the potential evapotranspiration of Haihe River Basin showed a significant downward trend. Gao et al ${ }^{[6]}$ studied the change trend of potential evapotranspiration in China. The potential evapotranspiration of Songhuajiang River basin has a significant upward trend. The results of literature [7-
9] show that the potential evapotranspiration of the upper and middle reaches of the Yellow River is on the rise, and Ma et al. ${ }^{[10]}$ believed that the the Yellow River basin was significantly reduced in Henan, Shaanxi and Shanxi, and there was no obvious trend in the northwest region, and the southwest region was increasing.

The annual average temperature of the Yellow River basin in recent years shows an upward trend. In 20002003 , it is $1.1{ }^{\circ} \mathrm{C}$ higher than that in 1956-1959. The annual average precipitation is $446.3 \mathrm{~mm}$ in 1956-2010, which gradually decreased from southeast to northwest ${ }^{[11]}$. At the same time, the runoff decreased obviously, compared with 1956-2000, the natural runoff of Huayuankou section in 2007-2014 was 13\% less, in which the Helong section was $56.4 \%$ less ${ }^{[12]}$, and the amount of green water increased, especially in the middle reaches of the Yellow River. Liu et al. ${ }^{[13]}$ found that from 2000 to 2013, the green water of all subbasins in the middle reaches of the Yellow River increased from 1980 to 1999, with an increase of $15.66-51.36 \mathrm{~mm}$. Therefore, under the background of significant changes in meteorological and hydrological conditions, it is very important to analyze the trend of potential evapotranspiration and its influencing factors in the Yellow River basin, which can provide the basis for water resources planning and management.

Based on the data of 90 meteorological stations in the Yellow River Basin, the potential evapotranspiration in the Yellow River Basin from 1952 to 2014 is calculated based on the Penman-Monteith formula recommended by FAO. The variation trend of the potential evapotranspiration in the Yellow River is analyzed by

*Corresponding author: lufan@iwhr.com 
using the Mann-Kendall trend test method. The effects of wind speed, temperature, radiation and relative humidity on potential evapotranspiration were analyzed.

\section{Study areas and methods}

\subsection{Study areas}

The Yellow River originates from the YoguZongjie basin in the northern foot of Bayan Kela Mountain on the Qinghai-Xizang Plateau. It winds eastward through the Loess Plateau and the Huang-Huai-Hai Plain and flows into the Bohai Sea. The main stream is $5464 \mathrm{~km} \mathrm{long}$, and the water surface drop is 4480 meters. The Yellow River basin is located between longitude $96{ }^{\circ} \mathrm{E}-119{ }^{\circ} \mathrm{E}$ and latitude $32{ }^{\circ} \mathrm{N}-42^{\circ} \mathrm{N}$ (fig. 1). It is about $1900 \mathrm{~km}$ long from east to west and $1100 \mathrm{~km}$ from north to south. The total area of the basin is 795000 square kilometers (including 42000 square kilometers of the inner flow area
). The river above the Hekou is the upper reaches of the Yellow River, the river course is 3472 kilometers long and the basin area is 428000 square kilometers. The middle reaches of the river from Hekou to Taohuayu are 1206 kilometers long and the basin area is 344000 square kilometers. The lower reaches of the Taohuayu river are 786 kilometers long. The basin covers an area of 23000 square kilometers. The average annual rainfall of the Yellow River basin is $438 \mathrm{~mm}$, and the average annual water surface evaporation in most areas is between 800 and $1800 \mathrm{~mm}$. The regional difference is large. The main high value area of water surface evaporation is in the area where the annual precipitation is less than $400 \mathrm{~mm}$. The annual average evaporation is $1390 \mathrm{~mm}$, and the total distribution is gradually reduced from northeast to southwest ${ }^{[12,14]}$. The northeast area is the largest area in the Yellow River basin, where the annual average evaporation is above $1750 \mathrm{~mm}$, while it in the southwest is below $1250 \mathrm{~mm}^{[14]}$.

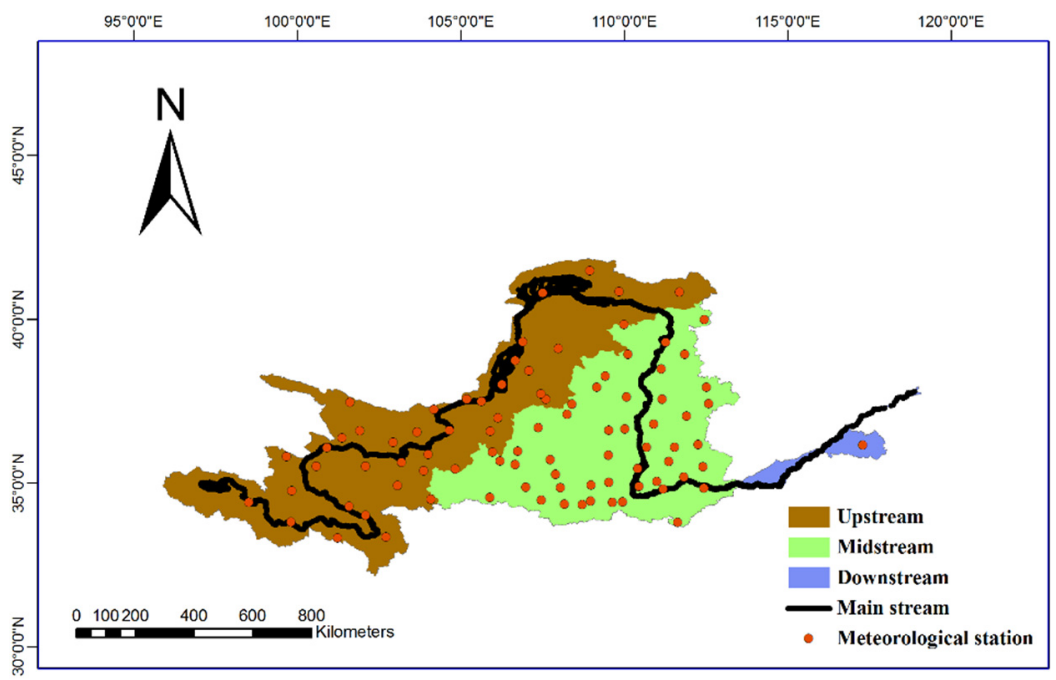

Fig. 1. Study Area

\subsection{Method}

(1) The Penman-Monteith formula recommended by the world food and Agriculture Organization (FAO).

$$
\begin{aligned}
E T_{0}=E_{\text {rad }}+E_{\text {aero }} \\
E_{\text {rad }}=\frac{0.408 \Delta\left(R_{n}-G\right)}{\Delta+\gamma\left(1+0.34 U_{2}\right)} \\
E_{\text {areo }}=\frac{\gamma \frac{900}{T+273.15} U_{2}\left(e_{s}-e_{a}\right)}{\Delta+\gamma\left(1+0.34 U_{2}\right)}
\end{aligned}
$$

$E T_{0}$ is potential evapotranspiration; $E_{\text {rad }}$ is radiation term; $E_{\text {aero }}$ is aerodynamic term; $\Delta$ is saturated vapor pressure gradient; $R_{n}$ is net radiation; $G$ is soil heat flux density; $\gamma$ is hygrometer constant; $U_{2}$ is wind speed at $2 \mathrm{~m} ; T$ is average temperature at $2 \mathrm{~m} ; e_{s}$ is saturated vapor pressure; $e_{a}$ is actual vapor pressure. (2) Mann-Kendall trend test

The trend of potential evapotranspiration over the years is calculated by the Mann-Kendall trend test method. Mann-kendall trend test was first proposed by Mann in 1945 (Mann, 1945) to test the trend of climate and hydrological time series data. It is widely used because it is not disturbed by data distribution characteristics, outliers and strong detection ability. This method assumes that for a fixed time series data $X=\left\{X_{1}, X_{2}, X_{3}, \ldots \ldots, X_{n}\right\}$, the formula for calculating the statistical value $\mathrm{S}$ is as follows:

$$
\begin{aligned}
& \mathrm{S}=\sum_{j=1}^{n-1} \sum_{k=j+1}^{n} s\left(X_{k}-X_{j}\right) \\
& \mathrm{s}\left(X_{k}-X_{j}\right)=\left\{\begin{array}{c}
+1, X_{k}>X_{j} \\
0, X_{k}=X_{j} \\
-1, X_{k}<X_{j}
\end{array}\right.
\end{aligned}
$$

$X$ represents the observational data with a certain time series (e.g., annual runoff depth, annual precipitation, evapotranspiration, etc.) $\mathrm{k}=1,2,3, \ldots, \mathrm{n}-1 ; \mathrm{j}=\mathrm{k}+\mathrm{l}$, $\mathrm{k}+2, \mathrm{k}+3, \ldots, \mathrm{n} ; \mathrm{n}$ represents the number of observed data.

The Mann-Kendall test statistic $\mathrm{Z}$ can be calculated by the following formula:

$$
\mathrm{Z}=\left\{\begin{array}{l}
\frac{S-1}{\sqrt{V(S)}}, S>0 \\
0, \quad S=0 \\
\frac{S+1}{\sqrt{V(S)}}, S<0
\end{array}\right.
$$

$V(S)$ is variance. This formula mainly uses $\mathrm{Z}$ value to study the significance test of trend statistics of series data. 
Firstly, it is assumed that there is no obvious change trend in the parameters of the time series detected, so the critical test value $Z 1-\alpha / 2$ at a certain significant level can be obtained by two-tail test. When $|\mathrm{Z}|<\mathrm{Z} 1-\alpha / 2$, the original hypothesis holds true; when $|\mathrm{Z}|>\mathrm{Z} 1-\alpha / 2$, the original hypothesis does not hold, and the parameters of the time series detected have obvious change trend. In the $95 \%$ confidence level, the critical value is $\mathrm{Z} 1-\alpha / 2=1.96$, and $Z 1-\alpha / 2=2.58$ at the $99 \%$ confidence level. The $95 \%$ confidence level is used in this paper.

\section{Trends of potential evapotranspiration in the Yellow River Basin}

Based on the meteorological data from 90 meteorological stations in the Yellow River Basin from the National Meteorological Center, the potential evapotranspiration of each meteorological station in the Yellow River Basin was calculated by Penman formula. The Mann-Kendall trend test was used to analyze the variation trend(Fig.2). Of the 90 meteorological stations in the Yellow River Basin, 43.3\% showed a significant upward trend in potential evapotranspiration, $30 \%$ showed a significant downward trend, and $26.7 \%$ had no obvious change trend. Among them, the upstream showed a significant upward trend, the middle showed a weak upward trend, and the downstream showed a weak downward trend. This is similar to the results of literature [4,7-9]. As can be seen from Figure 2, there are more stations in the middle reaches of the Yellow River, but the main reason for the weak upward trend of potential evapotranspiration in the middle reaches of the Yellow River is that the downward stations are more concentrated, the area occupied is smaller, and the basin area controlled by the upward stations is larger.

It can be seen from the figure 2 that the potential evapotranspiration declining stations in the secondary division of water resources in the Yellow River Basin are mainly concentrated in the north of Longyangxia to Lanzhou, the east of Longmen to Sanmenxia, and the stations above Longyangxia to Huayuankou. The stations above Longyangxia all increase significantly, and the stations below Huayuankou have no significant change. Other secondary water resources divisions have both stations with significant increases, decreases and no significant changes. Distribution is similar to that of literature [15], and has the same part as that of literature [10], but the final results are different, which may be due to the different length of the study sequence and site density.

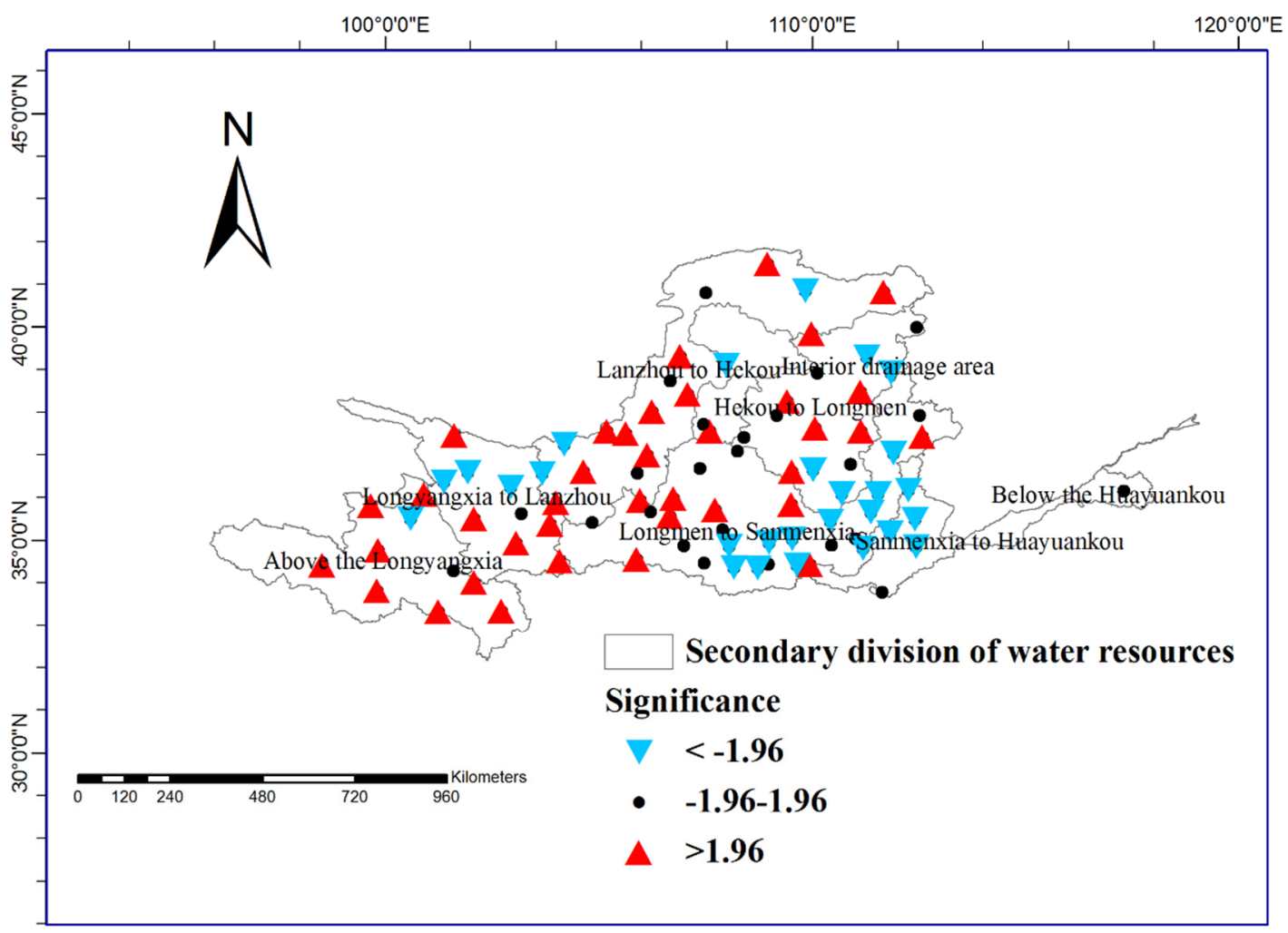

Fig.2. The trend of reference evapotranspiration of 90 meteorological stations in the Yellow River Basin from 1952 to 2014

Table 1 The trends and significance of reference evapotranspiration, radiation and aerodynamics in 1952-2014

\begin{tabular}{cccccc}
\hline \multirow{2}{*}{ Range } & \multicolumn{2}{c}{$\mathrm{ET}_{0}$} & \multicolumn{2}{c}{$\mathrm{E}_{\mathrm{rad}}$} & \multicolumn{2}{c}{$\mathrm{E}_{\text {aero }}$} \\
\cline { 2 - 5 } & $\begin{array}{c}\text { Tendency rate } \\
(\mathrm{mm} / 10 \mathrm{a})\end{array}$ & Significance & $\begin{array}{c}\text { Tendency rate } \\
(\mathrm{mm} / 10 \mathrm{a})\end{array}$ & Significance & $\begin{array}{c}\text { Tendency rate } \\
(\mathrm{mm} / 10 \mathrm{a})\end{array}$ \\
\hline
\end{tabular}




\begin{tabular}{ccccccc}
\hline Upstream & 4.74 & 2.21 & 3.79 & 4.6 & 0.95 & -0.19 \\
Midstream & 5.12 & 1.02 & 2.34 & 1.86 & 2.79 & 0.2 \\
Downstream & -1.27 & -0.31 & -6.93 & -5.16 & 5.66 & 1.87 \\
The Whole & 3.97 & 2.91 & 3.98 & 7.81 & -0.01 & -1.04 \\
basin & & & & & & \\
& & & & & &
\end{tabular}

\section{Analysis of meteorological factors affecting the change of potential evapotranspiration}

The Penman-Monteith formula shows that the potential evapotranspiration is mainly affected by sunshine hours, wind speed, temperature and relative humidity. The increase of sunshine hours, wind speed, temperature and the decrease of relative humidity will increase the potential evapotranspiration. The correlation coefficients between potential evapotranspiration, radiation, aerodynamics and wind speed, temperature, relative humidity and sunshine hours were analyzed by multiple linear regression method, and table 2 was obtained. Meanwhile, table 3 shows the tendency and significance of the change trend of meteorological elements in the the Yellow River Basin.
It can be seen from the analysis of the tables that the changes of radiation terms in the upper, middle and lower reaches of the Yellow River are more obvious than those in the aerodynamic terms. Temperature and radiation will affect the radiation in the potential evapotranspiration. The correlation coefficient between the temperature in Table 2 and the potential evapotranspiration in the Yellow River Basin and its upper, middle and lower reaches is large, and the temperature change also shows a significant upward trend, indicating that the significant temperature rise is the main reason for $43.3 \%$ stations in the Yellow River Basin to show a significant upward trend. The results of literature [4] are similar; 20 sites with significant declines in potential evapotranspiration from Longyangxia to the north of Lanzhou, east of Longmen to Sanmenxia and Sanmenxia to Huayuankou are concentrated, of which $65 \%$ are mainly affected by wind speed, which is similar to the results of literature [10].

Table 2 Correlation coefficients between climate variables and reference evapotranspiration, radiation and aerodynamics

\begin{tabular}{ccccc}
\hline \multirow{2}{*}{ Range } & $\begin{array}{c}\text { Meteorological } \\
\text { factors }\end{array}$ & $\begin{array}{c}\text { Potential } \\
\text { evapotranspiration }\end{array}$ & Radiation term & $\begin{array}{c}\text { Aerodynamics } \\
\text { term }\end{array}$ \\
\hline \multirow{4}{*}{ Upstream } & & & -0.45 & 0.72 \\
& Wind speed & 0.55 & 0.27 & 0.41 \\
& Temperature & 0.8 & 0.2 & 0.12 \\
& Sunshine hours & 0.34 & -0.09 & -0.47 \\
& Relative humidity & -0.35 & & \\
\hline \multirow{5}{*}{ Midstream } & & & -0.5 & 0.35 \\
& & & 0.8 & 0.22 \\
& Wind speed & 0.19 & 0.85 & 0.15 \\
& Temperature & 0.51 & 0.3 & -0.47 \\
& Sunshine hours & 0.47 & & \\
& Relative humidity & -0.35 & & 0.56 \\
& & & -0.88 & 0.32 \\
Downstream & Wind speed & 0.16 & 0.19 & 0.06 \\
& Temperature & 0.41 & 0.79 & -0.73 \\
& Sunshine & 0.44 & 0.13 & 0.55 \\
& hoursRelative & -0.68 & & 0.39 \\
& humidity & & -0.34 & 0.21 \\
The whole & Sunshine hours & 0.41 & 0.55 & -0.49 \\
& Relative humidity & -0.56 & -0.07 &
\end{tabular}

Table 3 Probability and significance of climate variables in the period 1952-2014

\begin{tabular}{ccccccccc}
\hline & \multicolumn{2}{c}{ Wind speed } & \multicolumn{2}{c}{ Temperature } & \multicolumn{2}{c}{ Sunshine hours } & \multicolumn{2}{c}{ Relative humidity } \\
\cline { 2 - 9 } Range & $\begin{array}{c}\text { Tendency } \\
\text { rate } \\
\left(\mathrm{m}^{*} \mathrm{~s} / 10 \mathrm{a}\right)\end{array}$ & $\mathrm{Z}$ & $\begin{array}{c}\text { Tendency } \\
\text { rate }\left(^{\circ}\right.\end{array}$ & $\mathrm{Z}$ & $\begin{array}{c}\text { Tendency } \\
\text { rate } \\
\mathrm{C} / 10 \mathrm{a})\end{array}$ & $\mathrm{Z} / \mathrm{m} / 10 \mathrm{a})$ & $\begin{array}{c}\text { Tendency } \\
\text { rate } \\
(\% / 10 \mathrm{a})\end{array}$ & $\mathrm{Z}$ \\
\hline Upstream & -0.54 & -5.47 & 2.22 & 5.48 & -0.42 & -3.37 & -0.75 & -3.64 \\
Midstream & -0.36 & -4.02 & 3.65 & 6.93 & -1.02 & -4.23 & -0.56 & -2.05 \\
\hline
\end{tabular}




\begin{tabular}{ccccccccc}
\hline Downstream & 0.48 & -0.66 & -1.80 & -7.91 & 0.15 & 1.94 & 1.98 & 8.28 \\
$\begin{array}{c}\text { The whole } \\
\text { basin }\end{array}$ & -0.60 & -11.52 & 2.95 & 11.65 & -0.81 & -8.37 & -0.57 & -4.62 \\
\hline
\end{tabular}

\section{Conclusion}

(1) $43.3 \%$ of the 90 meteorological stations in the Yellow River Basin showed a significant upward trend. $30 \%$ of the stations showed a significant downward trend. 26.7\% of the stations had no obvious trend of change. Among them, the potential evapotranspiration of upper and middle reaches showed an upward trend, a significant change in upstream trend, and a weak downward trend in lower reaches. The potential evapotranspiration ofLongyangxia to the northern part of Lanzhou, Longmen to the eastern part of Sanmenxia, and Sanmenxia to Huayuankou in the eight secondary water resources areas of the Yellow River basin has a significant downward trend, and the stations above Longyangxia have increased significantly. The change trend of the sites below Huayuankou was not significant. Other sites with rising, declining and no significant changes are distributed.

(2) The variation of radiation in the upper, middle and lower reaches of the Yellow River is more obvious than that in aerodynamics. The radiation in the upper and middle reaches of the Yellow River rises significantly, while that in the lower reaches decreases significantly. Through correlation analysis, it is found that the significant increase of potential evapotranspiration at some stations is the increase of temperature, and the decrease of wind speed has a significant effect on the potential evapotranspiration from Longyangxia to northern Lanzhou, Eastern Longmento Sanmenxia, and Sanmenxia to Huayuankou.

\section{Acknowledgments:}

This study was supported by the National Key R\&D Program of China (2017YFC0404401) and the national Natural Science Foundation of China(Grant No. 51679252).

\section{References}

1. Yin Y.H., Wu S.H., Dai E.F., CS, 55, 2226(2010).

2. D.Rind, R.Goldberg, J.Hansen, C. Rosenzweig, R. Ruedy, JGR, 9983(1990).

3. Han S.J., Liu Q.C., Yang S.J., JWU, 42, 734(2009).

4. Liu C.M., Zhang D., JG, 66,579(2011).

5. Zhao N., Wang Z.G., Zhang F.M., Li Z., SNWTWST, 15,11(2017).

6. Gao G., Chen D.L., Ren G.Y., Chen Y., Liao Y.M., GR, 25, 378(2006).

7. Gao G., Chen D., Xu C.Y., E. Simelton, JGR, 112(2007).

8. Wang Y.J., Li J., Lin Z.H., SSWC, 11, 48(2013).
9. Zhang F.M., Shen S.H., JNIM, 30, 706(2007).

10. Ma X.N., Zhang M.J., Wang S.J., Ma Q., Pan S.K., AGS, 67, 645(2012).

11. Xia J., Peng S.M., Wang C., Hong S., Chen J.X., Luo X.P., YR, 36, 1(2014).

12. Liu X.Y., Causes of Water and sediment reduction in the Yellow River in recent years (Science press, 2016).

13. Liu C.M., Li Y.Z., Liu X.M., Bai P., Liang K., YR, 38, 7(2016).

14. Liu C., Wang S.R., Liang Y.Y., R. L. Leung, PIDC, 9, 327(2013) 